\title{
Transformative Education: Students in the Spotlight - A Holistic Pedagogical Approach
}

\author{
Dina El Achi ${ }^{1}$, Nabil M. Halabi ${ }^{2}$, Bilal R. Kaafarani ${ }^{3,}$, \\ ${ }^{1}$ Faculty of Medicine, American University of Beirut, Beirut, Lebanon \\ ${ }^{2}$ Department of Biology, American University of Beirut, Beirut, Lebanon \\ ${ }^{3}$ Department of Chemistry, American University of Beirut, Beirut, Lebanon
}

Email address:

dae17@mail.aub.edu (D. El Achi),nmh67@mail.aub.edu (N. M. Halabi), bilal.kaafarani@aub.edu.lb(B. R. Kaafarani)

*Corresponding author

\section{To cite this article:}

Dina El Achi, Nabil M. Halabi, Bilal R. Kaafarani. Transformative Education: Students in the Spotlight - A Holistic Pedagogical Approach. Science Journal of Education. Vol. 7, No. 5, 2019, pp. 107-113. doi: 10.11648/j.sjedu.20190705.12

Received: October 7, 2019; Accepted: October 23, 2019; Published: October 31, 2019

\begin{abstract}
Inspired by the shortcomings of traditional pedagogical approaches to post-secondary education, the Primary Investigator created from first principles a new educational initiative termed Transformative Education. Rejection of conventional teacher-student dynamics and classroom-centric learning stand at the core of this new modus operandi, which began at the American University of Beirut (AUB). In its place, the PI proposed Transformative Education to widen the breadth of learning to occur mainly outside of the classroom and to shift the locus of control into the hands of the students. The new teaching style is explored through several subsidiary initiatives, beginning first with the establishment of the Organic Chemistry Club (OCC). The OCC initially brought together students of the discipline to administer student-lead tutoring clinics but soon began to incorporate pupils of diverse majors to work on larger scale projects. The series of Organic Chemistry Competitions (OC) were the pioneering event, which utilized the Personal Response System to bring together undergraduates in an international competition. The model set forth by these series of competitions, one of local organization by the student body to host a large scale event with international participants, was proven to be generalizable to any discipline, as evidenced by the subsequent Medical Competitions. Following in line with the staple of students being at the epicenter of Transformative Education, the PI crafted the undergraduate Medical Research Volunteer Program (MRVP), a platform of experiential learning whose establishment has resulted in multiple publications and awards. Another series of events aimed at students are the Mentoring, Makhlouf Haddadin, and IgNobel Lectureships, which consistently see significant student turnout seeking career/life counseling, chemical innovation and scientific curiosities, respectively. Another initiative lies in the annual ChemCarnival. Said celebration of chemistry through visual demonstrations of extravagant experiments summarizes the entire Transformative Education drive by demonstrating both core tenants of extra-curricular involvement and student engagement. It is the opinion of the PI that the success of this new approach be taken together and not by viewing each event individually; the Gestalt of this new pedagogical approach is more than the arithmetic sum of its parts. Through experimentation with several initiatives, it is clear to see that the results demonstrate a sustained and tangible impact on the careers of students, advocating the further use and development of Transformative Education.
\end{abstract}

Keywords: Transformative Education, Experiential Learning, Outreach Activities

\section{Introduction}

Academic excellence may be defined as a reciprocal situation in which a student's ability to achieve their goals is not solely dependent on the students themselves, but also on the teacher's readiness to mold knowledge and ideas into their minds [1]. This may satisfactorily be achieved through a paradigm of thought, knowledge and performance that teachers use to customize their own teaching style.

However, teaching approaches vary widely and educators must properly pick their methodologies with respect to their audience. Teachers of scientific disciplines (such as 
chemistry) are often presented with unique challenges when reaching out to their students. A commentary on collaborative teaching in chemistry suggested that effective teaching stems from relating chemical concepts to real life experiences, rather than presenting students with an abstract outline of the material [2]. Thusly, chemists often attempt to build new and interesting frameworks to convey to their students the fundamental ideas of chemistry, by shifting to innovative techniques such as use of computational methods (e.g. software simulations), educational travel experiences and seminars to attain a fruitful educational experience [3]. Another study [4] suggested that the use of a web-based student response system is extremely helpful in assessing the comprehension of quantitative analysis courses, where students would not only be actively engaged in the classroom itself but would also compare their level of comprehension to the rest of the class. For years, scholars that categorize teaching styles have attempted to classify educators and identify their means of teaching. Yet, there are still new teaching approaches that are emerging, specifically ones that give preferential prominence to the audience at hand; the students.

Founded in 1866, the American University of Beirut (AUB) is a prestigious teaching-centered research university in Beirut, Lebanon known for its exemplary teaching methods throughout the region. This commentary chronicles the Primary Investigator's personal experience at the AUB in developing his own transformative and holistic teaching style. The aforementioned style describes various methods of recognizing the unique qualities in students and tempering them into the building blocks that contribute to remarkable projects and thrilling endeavors. In doing so, students are exposed to a plethora of knowledge and are empowered to become creative and assertive leaders. Professional success is not only an educational endeavor but a personal one as well; this was the principle force driving the creation of said platform, for students to shine by embracing their untapped potentials.

\section{All Students Are Gifted; The Organic Chemistry Club}

To begin, one must realize that although the ultimate locus of control resides within the students, the role of the teacher is also important and cannot be entirely neglected. However, contrary to conventional methods which place the educators' role confined within the physical limits of the classroom, this transformative education approach stresses that they can express their investment in students' progress outside the classroom as well. This was exemplified in 2010 when the PI began gathering talented students from different majors to create, by 2013, an active student taskforce; the Organic Chemistry Club (OCC). The OCC has and continues to be a hub for academic engagement and creative projects. Previous studies have suggested that peer instruction is an effective approach to instruction [5]. One of the first OCC's missions, then, was to launch the Organic Clinic. Thus defined, the Organic Clinic is a service provided by OCC members who have previously excelled in Organic Chemistry courses which offer free tutoring to students in need of help.

Throughout the years, the OCC has grown beyond its origins in the Organic Clinic, with each member now having the chance to showcase his/her unique talent(s) by demonstrating their exceptional ideas through educational events and projects. All members are offered a place in the spotlight, performing their skills to the utmost of their capabilities. Some members design posters for upcoming events, others conduct live reporting and interviews with attendees whilst still others showcase their talents in dancing and singing to promote educational events at the AUB (to name but a few examples).

Members of the OCC were able to thrive both personally and academically. In fact, four students from the PI's team were recipients of the Penrose Award (the most prestigious award given to an outstanding student in terms of scholarship, character, leadership and contribution to university life at the AUB), while others were granted the Philip Hitti Award (given to outstanding students in the AUB Faculty of Arts and Sciences). Members of the OCC have also had the chance to land top programs in prestigious universities abroad.

True to the focus of allowing the pupils (and not exclusively the teacher) to take on tasks, the student team has constantly played a significant role in the creation and organization of many transformative educational initiatives. These include the non-exhaustive list consisting of the International Organic Chemistry Competition, the Medical Competition, the Mentoring Talks, the Makhlouf Haddadin Lectureship, the ChemCarnival and many others (all of which are to be described later in this manuscript).

\section{The International Organic Chemistry Competition (OC)}

The first staple in this list of student-led accomplishments finds itself at the heart of chemical education. In 2009, the PI introduced the Personal Response System [6] (also known as 'clickers') into organic chemistry classes at the AUB. To test their comprehension of the material, students were grouped into pairs and presented with multiple-choice questions that they answered with their clickers. Initially, the use of clickers was intended to elicit an active learning environment in organic chemistry classes and to invite students to enhance their critical thinking capabilities. However (to the surprise of the PI), students' enthusiasm and dynamic involvement in solving problems through the Personal Response System was so enthusiastic that it led to its use beyond the walls of the classroom. 


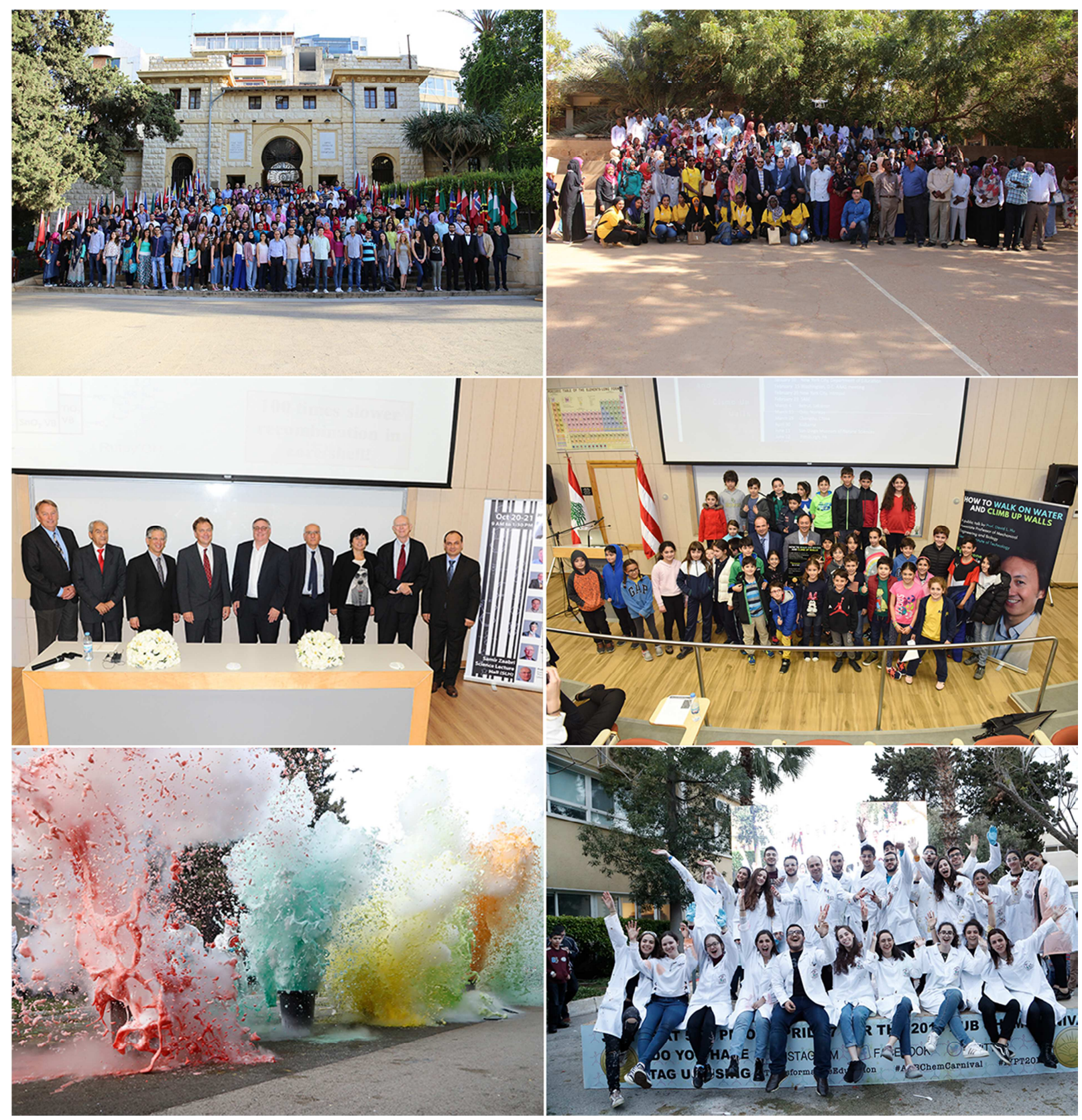

Figure 1. Top left: Group photo during the Fourth International Organic Chemistry Competition (OC4). Top right: Group photo during the Third Organic Chemistry Competition in Africa at Ahfad University for Women (OC3-AUW). Middle left: Group photo during the 2016 Makhlouf Haddadin Symposium organized on the occasion of the AUB's 150th anniversary (from left to right: Professors Kurth, Haddadin, Weiss, Meyer, Marder, Zard, De Cola, Whitesides and Kaafarani). Middle right: Group photo with some of the young audience members attending the public talk of Ig Noble prize winner Prof. David Hu. Bottom left: Soap explosion during the 2019 AUB ChemCarnival. Bottom right: The 2019 Transformative Education team after the 2019 AUB ChemCarnival.

In 2011, the PI was appointed by the International Union of Pure and Applied Chemistry (IUPAC) as the coordinator of its activities in Lebanon in celebration of the International Year of Chemistry (IYC2011). This endowment, combined with the use of the Personal Response System, manifested itself in the Organic Chemistry Competition (OC) [7]. It is worthy to note that the scale of the endeavor far exceeded what was initially anticipated. What began as an event only gathering students from local universities advanced to an international competition containing over 120 participating teams from 17 universities originating from a total of 7 countries. To date, four OC events have taken place at the
AUB during 2011 (OC1), 2012 (OC2), 2014 (OC3), and 2016 (OC4). The Fifth International Organic Chemistry Competition (OC5) is scheduled to take place in January 2020. Videos of all OC events may be found on the PI's YouTube channel [8]. The Organic Competitions not only provided students with an opportunity to delight in the recognition of their skills but also acted as a platform for the participants to showcase their talents and demonstrate active engagement. To highlight the success of OC3 and OC4, members of the OCC utilized their creative side by editing trailers for the aforementioned competitions, as well as by autonomously conducting live reporting and interviews each 
year. The students also embraced the fun of chemistry by creating video clips entitled Organic Chemistry Style [9] and OC Number Four [10] to promote the OC3 and OC4, respectively. The video clips, trailers and interviews are all posted on YouTube $[8,11]$. The posters for the Organic Competition reached over 250 universities worldwide during the preparation for $\mathrm{OC} 4$, and several advertisements about the competition were posted on the websites of prestigious international chemistry journals. The OC (Figure 1) has now become a platform of higher education, where students from all over the globe can showcase their skills by solving challenging organic chemistry problems in a dynamic and enthusiastic manner. Following its significant success, a manuscript highlighting the inception, rules, and triumph of the competition was published [12]. Furthermore, in inspiration of the $\mathrm{OC}$ and in coordination with the AUB Regional External Programs, the "Across Borders Organic Competition" was organized by the PI at the Afhad University for Women in Sudan (Figure 1). It is of high relevance to note that organic chemistry is only one of the many fields in which such a model for competitions may be replicated. The $\mathrm{OC}$ can be used as an educative model to encourage teamwork and can certainly enable the connection of students across diverse disciplines, age cohorts, and populations from all around the academic world.

\section{Medical Competition (MC)}

As if to demonstrate the applicability of the previously made point, the first ever Medical Competition (MC) was established at the AUB in September 2018. This was of course done in accordance with the model established by the OC. Participants in the MC consisted of 116 students studying in six medical schools across Lebanon. As was the case with the OC, laughter during success, anguish at not knowing the correct answer, and general excitement filled the room throughout the competition. Students were presented with challenging medical cases pertaining to various specialties and had to choose a correct answer from amongst a list of 4-7 choices (the questions were prepared by a committee of physicians from the AUB Medical Center [AUBMC]). Similar to the OC model, the MC was comprised of two rounds: in round 1, the teams answered 10 questions using programmed clickers. Teams that answered at least half of the questions correctly advanced to the second round. Therein, participants were evaluated based on the number of correct responses and the speed with which they answered (in a 'blitz' like round). The students were not only enthusiastic to win cash prizes but enjoyed the thrill of the competition, in addition to the possibility of winning two medical electives in the USA. The medical competition, although now only operational at the local level, strives to become a hub for aspiring physicians around the world to connect, share insight and test their medical knowledge [13]. A study suggested that a medical student's problem solving skills is ranked $10^{\text {th }}$ in the core elements of medical professionalism, with communication skills being ranked $5^{\text {th }}$
[14]. Most recently, a medical competition among medical residents (RMC) from different specialties across Lebanon was also conducted. Through such a competition, the physicians of tomorrow may enhance their interpersonal capabilities as well as systematic thinking, which are undoubtedly assets to future medical doctors in any environment.

\section{An Innovative Experiential Learning Initiative: The Medical Research Volunteer Program}

In continuing with the trend of learning through action, further initiatives were specifically crafted to give students opportunities to explore their talents and interests in situ. Experiential learning may perhaps be defined as assembling knowledge and meaning through real life-experiences. Educational theorist David Kolb recognizes four stages in experiential learning: concrete experience (referring to the encounter of a new experience, or the reassessment of a past experience), reflective observation (of said new experience), abstract conceptualization (where new ideas emerge or preexisting ones are modified), and finally active experimentation of these experiences (to observe results) [15]. In medical education, the optimal method of learning is by doing, and through comparing and contrasting old and new experiences, future physicians are able to maximize their potential for beneficial learning [16].

This emphasis on participatory learning is also relevant to students intending to enter medical school as well (i.e. premedical students). However, many of these students are confused and lack the necessary information to make an informed decision about their career paths in medicine. In order to enable students to see a possible path for themselves, experiential learning was employed at the AUB by developing a unique program which exposed undergraduate students to medical research early on in their career, suitably termed the Medical Research Volunteer Program (MRVP). The MRVP provides volunteering undergraduates the opportunity to shadow and learn from physicians, clinical researchers, basic science researchers, and other health-care professionals. By filling out their profile on an online portal, students are matched with researchers based on their areas of interest and the type of research they are willing to conduct. In joining the MRVP, students become an integral part of a medical research team, which they aid on a continual basis. When students are successfully matched, they are promptly sent an email containing the goal of the project, its duration and the investigator overseeing it. Since its inception in 2013 and up to this date, the MRVP has matched up to 701 undergraduates to work on 224 projects with 97 faculty members from the AUB Faculty of Medicine. To date, 25 students from the MRVP have coauthored 18 published manuscripts in international peer-reviewed medical journals with their respective principal investigators. The students 
enrolled in the MRVP have had the exceptional opportunity to be exposed to a real research experience, surpassing what is offered by the standard university curriculum. Each year, two students are recognized for their outstanding work in the MRVP and are granted the "Ibrahim and Loulou Durr Endowed MRVP Award," as well as a cash prize of 1,000 USD (each). The MRVP is a pioneer program that allows undergraduates to satisfy their curiosity and attain a deeper knowledge of medical research. In an effort to deepen the educational component of the MRVP experience, the overseeing MRVP committee has conducted workshops open to all undergraduate students in order to introduce the basics of scientific research to them. A manuscript describing the MRVP as a potential model program that may be implemented in other institutions was recently published as well [17].

\section{Mentoring Seminars}

As useful and empowering as experiential education is for students to take initiative amongst themselves, one must also lend credence to other models of psychological development and learning. According to Lev Vygotsky, learning takes place when a student is guided and mentored by a More Knowledgeable Other (MKO) in order to help them achieve goals which are slightly beyond their current skill-set (termed the Zone of Proximal Development) [18]. As such, an essential step of acquiring new skills is for the educator to facilitate this relationship between mentors and mentees. Such a mentoring relationship is ideally built on trust between the two parties involved. Effective mentors choose not to coerce but rather encourage the mentee. This is important for they must also foster independence when the mentee has achieved their goals [19]. Furthermore, studies in support of this conclusion have suggested that mentoring is key in assisting students with their future career endeavors [20]. Bearing this in mind, the Primary Investigator has launched several initiatives at the AUB (beginning in 2016 with the Mentoring Talks [21]) whose focus is to provide students with role models of success, perseverance, and diligence who may help them progress above and beyond their Zone of Proximal Development. Throughout the year, world-renowned speakers are invited to give eponymous mentoring talks to inspire, advise and guide students throughout their academic journey. Through the talks, students from all majors at the AUB and other institutions are prompted to assess where they are in their career path and identify any weaknesses they may have. Moreover, students often see progress in others more readily than they do in themselves, and it is by self-identifying with these guest speakers that inspiration blossoms to drive the student to ultimately succeed [22]. Mentoring has the intent of bringing to the forefront of the students' conscience that challenges are natural and to be expected on one's journey; and it is how we react to such adversity which defines who we are [23]. To date, mentoring seminars have been delivered by well- renowned professors including Chemistry Nobel Laureate Sir Fraser Stoddart [24], a physician, an international stand-up comedian, successful businessmen and TV anchors among other professionals. Additionally, students have had the opportunity to personally meet the speakers, share their aspirations and receive unprecedented advice from the More Knowledgeable Other(s).

\section{Students' Exposure to Exceptional Individuals in Chemistry: The Makhlouf Haddadin Lectureship}

Considering that the original basis for the Transformative Education model was chemistry, the PI decided to dedicate a particular lectureship to students of the discipline. In 2011, a drive was launched to establish an endowment in the name of Professor Makhlouf J. Haddadin (a distinguished chemistry professor at the AUB). Ever since, the proceeds of the Makhlouf Haddadin Endowment have been used to fund the annual Makhlouf Haddadin Awards for outstanding graduating students in chemistry. Furthermore in 2015, the Makhlouf Haddadin Lectureship was established as a platform where world-renowned chemists (including Nobel Laureates in Chemistry) are invited to deliver inspiring research talks at the AUB. Not only do students benefit from the content of these interactive lectures, but they are also able to actively engage with the lecturer post-seminar in a two-way question and answer session. Such exposure to scientific giants has led to recognition on the parts of the students as well; indeed, some students went on to perform $\mathrm{PhD}$ programs with prestigious guest speakers they met at the talks. This endowment created a window of opportunity for students and faculty alike, through hosting some of the brightest contemporary chemists at the AUB. To date, eleven internationally renowned chemists have delivered plenaries in this lectureship, with more expected each year (Figure 1) [25].

\section{Public Talks by Ig Nobel Prize Winners}

In regards to the two aforementioned lectureships, it is clear to see that their intended audience encompasses a scholarly and academic demographic, consisting mostly of university students and staff. However, the PI did not want such initiatives to solely appeal to adult audiences but rather sought to allow all people in attendance (including children) to be able to walk away with new ideas in their mind. These characteristics seemed to recommend themselves to talks by winners of the IgNobel Prize. First coined by Marc Abrahams, Ig Nobel Prizes are granted every year to ten individuals who "make people LAUGH, and then THINK" [26]. In March 2019, a new catalytic initiative of the Transformative Education drive was launched at the AUB whereby winners of the $\mathrm{Ig}$ 
Nobel Prize are invited to give public talks. Such talks spark attention and curiosity in science among audience members of all age cohorts, starting as young as six years old, Figure 1. This new drive aims to host Ig Nobel Prize winners every year for a wide-reaching and approachable public talk [27].

\section{From the Students to the Community: The ChemCarnival}

Perhaps no singular endeavor embodies the core principles of Transformative Education more than does the annual event of the ChemCarnival, first established in 2017. During the ChemCarnival, OCC students perform thrilling chemistry experiments on stage for a wide array of eager spectators. After months of meticulous preparation and experimental trials, the first ChemCarnival took place on April $28^{\text {th }}, 2017$. AUB staff, students, as well as other guests of all ages attended the event and were exhilarated by the numerous fun and large-scale chemistry experiments. For the duration of the event, OCC students transformed into professional chemists, showcasing the creative science behind chemistry. For the students empowered to conduct these chemical reactions, the ChemCarnival served as a training activity in communicating chemical knowledge to laypersons (thus practicing their interdisciplinary diplomacy). Students also became aware of a very significant rule in the world of scientific experiments; safety. For this, the AUB's Environmental Health, Safety and Risk Management Department sensitized students to be vigilant about safety precautions. On the other hand, attendees (especially younger generations) discovered the use of chemistry outside the walls of the classroom and were able to foster a sense of curiosity for the chemical sciences. What better way to convey the beauty of chemistry than by grandiose experiments? The ChemCarnival has become an annual event where students of the OCC brainstorm potential experiments and develop methods in which they can entertain an ever-growing audience. The 2018 and 2019 AUB Chem Carnivals attracted even bigger crowds, louder cheers and more experiments [8, 11]. The ChemCarnival has become an AUB spring tradition by which students have transcended the traditional ways in which chemistry can be applied, Figure 1. Details and videos on the three ChemCarnival events may be found on the ChemCarnival website [28].

\section{Whole Greater than the Sum of its Parts: A Gestalt of Transformative Education}

The pedagogical approach described in this commentary is realized not by analyzing any one initiative individually but rather by viewing it as a unified hole. Stated in other terms, students may find greater value in this school of thought as a whole, by implicitly gaining life-lasting skills through their participation in any/all of these endeavors. With the implementation of this holistic approach, some students find themselves gripped by a feeling of ecstasy in having an internal locus of control and taking on leadership roles. This pedagogical approach achieves its maximal potential as a holistic one, rather than simply the arithmetic sum of its individual parts.

\section{Conclusion}

In flipping the educational experience on its proverbial head, a teaching model was created which revolves around the continuous generation of opportunities for all students willing to put in the effort. The spectrum containing all such opportunities is far-spanning and encompasses a large breadth of human talents. The creation of these unique platforms prioritized students' needs, passions and originality through effective mentoring, substantially engaging students every step of the way. Thusly, said proposed model of Transformative Education is one that unifies classical methods as well as extra-curricular participation; hopefully to the successful implementation in other institutions as well. The cornerstone of any such derivative initiative would be the same as that of Transformative Education; namely, the dramaturgical metaphor that it is the student that should always be in the spotlight.

\section{Acknowledgements}

B. R. K. would like to acknowledge the great efforts, dedication, and devotion of all members of his transformative education team throughout the years since 2010 .

\section{References}

[1] A. S. Shaari, N. M. Yusoff, I. M. Ghazali, R. H. Osman, and N. F. M. Dzahir (2014). The Relationship Between Lecturers' Teaching Style and Students' Academic Engagement. Procedia - Social and Behavioral Sciences 118, 10-20.

[2] K. Klara, N. Hou, A. Lawman, and L.-Q. Wang (2013). Developing and Implementing a Collaborative Teaching Innovation in Introductory Chemistry From The Perspective of an Undergraduate Student. Journal of Chemical Education 90, 401-404.

[3] G. Trammell, P. F. M. Koehler, D. W. Pratt, V. N. Garkov, R. R. Gotwals, M. R. Wang, and A. Bishop (2010). Meeting The Challenges of Teaching Chemistry for General Education Students: Summary of The Fall 2007 ConfChem Conference. Journal of Chemical Education 87, $1455-1457$.

[4] J. P. Grinias (2017). Making a Game Out of It: Using WebBased Competitive Quizzes for Quantitative Analysis Content Review. Journal of Chemical Education 94, 1363-1366.

[5] B. J. Brooks and M. D. Koretsky (2011). The Influence of Group Discussion on Students' Responses and Confidence During Peer Instruction. Journal of Chemical Education 88, $1477-1484$. 
[6] M. J. Nee (2010). Book Review of Clickers in Action: Increasing Student Participation in General Chemistry by Margaret R. Asirvatham. Journal of Chemical Education 87, 784.

[7] Web page for the Organic Chemistry Competition. http://www.aub.edu.lb/fas/chemistry/oc (accessed October 2019).

[8] Prof. Bilal R. Kaafarani's YouTube channel, featuring videos of all competitions and other Transformative Education events. https://www.youtube.com/user/BilalRKaafarani (accessed October 2019).

[9] Video of "Organic Chemistry Style". http://youtu.be/eWuj_x3tbvE (accessed October 2019).

[10] Video of "OC Number Four". https://youtu.be/TqUsdWYEKiY (accessed October 2019).

[11] OCC's YouTube channel, featuring some interviews conducted by a student from the PI's team. https://www.youtube.com/channel/UCq1EWS2wU_ZoiTNH3 OBErQg (Accessed October 2019).

[12] L. I. Khalil, K. M. Chahine, and B. R. Kaafarani (2015). International Organic Chemistry Competition: A Thrilling, Unique Experience. Journal of Chemical Education 92, 401-404.

[13] Web page for the Medical Competition. http://www.aub.edu.lb/mc (accessed October 2019).

[14] Y. Hur and S. Kim (2009). What Qualities Do Medical School Applicants Need to Have? - Secondary Publication. Yonsei Medical Journal 50, 427-436.

[15] D. Sălăvăstru (2014). Experiential Learning and the Pedagogy of Interrogation in the Education of Adults. Procedia - Social and Behavioral Sciences 142, 548-552.

[16] S. Yardley, P. W. Teunissen, and T. Dornan (2012). Experiencial Learning: Transforming Theory Into Practice. Medical Teacher 34, 161-164.

[17] M. M. Dagher, J. A. Atieh, M. K. Soubra, S. J. Khoury, H.
Tamim, B. R. Kaafarani (2016). Medical Research Volunteer Program (MRVP): Innovative Program Promoting Undergraduate Research In The Medical Field. BMC Medical Education 16, 160.

[18] L. S. Vygotsky, The Collected Works of LS Vygotsky: Problems of the theory and History of Psychology; Springer Science \& Business Media, 1997; Vol. 3.

[19] A. Brewerton (2002). Mentoring. Liber Quaterly 12, 361-380.

[20] A. C. Iversen, N. A. J. Eady, and S. C. Wessely (2014). The Role of Mentoring In Academic Career Progression: A CrossSectional Survey of The Academy of Medical Sciences Mentoring Scheme. Journal of the Royal Society of Medicine 107, 308-317.

[21] Web page for the Mentoring Talks. http://www.aub.edu.lb/mentoringtalks (accessed October 2019).

[22] J. A. Nottingham, J. Nottingham, and M. Renton, Challenging Learning Through Dialogue: Strategies to Engage Your Students and Develop Their Language of Learning 2016.

[23] V. E. Frankl, Man's Search For Meaning; Simon and Schuster, 1985

[24] Video of Sir Fraser's mentoring talk. https://youtu.be/TThzr6FADWc (accessed October 2019).

[25] Web page for the Makhlouf Haddadin Awards and Lectureships. http://www.aub.edu.lb/haddadin (accessed October 2019).

[26] Web page for the Improbable Research. https://www.improbable.com (accessed October 2019).

[27] Web page for the Public Talks by Ig Nobel Prize winners at AUB. http://www.aub.edu.lb/ignobel (accessed October 2019).

[28] Web page for the ChemCarnival. http://www.aub.edu.lb/chemcarnival (accessed October 2019). 